\title{
Morphology and stability of Au nanoclusters in HOPG nanopits of well-defined depth
}

\author{
M. Hugentobler, S. Bonanni, A. Sautier, and W. Harbich ${ }^{\mathrm{a}}$ \\ Institute of Condensed Matter Physics, Ecole Polytechnique Fédérale de Lausanne (EPFL), 1015 Lausanne, Switzerland
}

Received 17 September 2010 / Received in final form 26 November 2010

Published online 14 January 2011 - (C) EDP Sciences, Società Italiana di Fisica, Springer-Verlag 2011

\begin{abstract}
Gold nanoparticles with a diameter comprised between 4 and $6 \mathrm{~nm}$ are stabilized in nanosized pits of well defined depth in highly oriented pyrolytic graphite (HOPG). These pits are produced by creation of artificial defects, followed by etching under a controlled oxygen atmosphere. At low Au coverage, clusters are found on the edges of the hexagonal pits maximizing the contact to dangling bonds on graphite multisteps. Larger coverage results in Au beads of surprisingly well defined shape and with a constant bead density per unit length. Most remarkable is the stability of these nanostructures under ambient conditions. Temperatures as high as $650 \mathrm{~K}$ do not alter the morphology of the gold clusters. Higher temperatures do not lead to a change of the cluster morphology but to catalytically driven etching of the HOPG substrate.
\end{abstract}

\section{Introduction}

Gold nanoparticles have attracted considerable interest in the past decade due to their geometrical, electronic and chemical properties which differ drastically from those of bulk material [1-6]. Bulk like gold is known as an extremely stable and established weak chemisorber, therefore a poor catalyst. The seminal work of Haruta [2,7] has evidenced that gold shows surprisingly strong catalytic activity when dispersed as nanoparticles on a substrate. Since then a large amount of chemical reactions have been identified on different substrates [8] and for free gold clusters [9]. The size ranges in which these activities are reported are however not clearly defined and depend on the substrate and the catalytic reaction. Valden et al. [10] clearly delimited the size range for active Au clusters on titania to be below $5 \mathrm{~nm}$ for the oxidation of CO. Turner et al. [4] found an upper limit of $2 \mathrm{~nm}$ for the oxidation of styrene by dioxygen for Au clusters supported on boron nitride, silicon dioxide and carbon. Even smaller sizes have been reported. Using mass selected clusters, catalytic activity to $\mathrm{Au}_{n}$ cluster with $(n \geq 7)$ [11-13] on $\mathrm{MgO}$ and $\mathrm{TiO}_{2}$ substrates could be assigned. These exciting results have created a new field known as nanocatalysis by gold [8].

The basal plane of HOPG having all carbon bonds saturated is extremely inert with a small energy barrier for adatom diffusion. Consequently it is difficult to stabilize nanoparticles on the surface terraces and aggregation takes place at mono-atomic step edges [14-17]. This results in a strongly anisotropic distribution of nanoparticles on the surface like metallic chains [15], a difficult size control and even more important in a small particle density. An important issue in this context is to find a

\footnotetext{
a e-mail: wolfgang.harbich@epfl.ch
}

way to stabilize these nanostructures [18-21]. A possible way is to pin the particles via the creation of defects to the surface [22-28]. However these structures although to some extent stable under vacuum conditions at room temperature alter upon exposure to atmospheric conditions or when immersed in solutions. Instead of stabilizing the particles by partial implantation of the cluster atoms one can imagine to keep them in place on strongly nanostructured surfaces.

HOPG is a model candidate for such type of substrates. Braeuchle et al. [29,30] were the first to create controlled nanosize pits in ion bombarded HOPG. These pits could be created by selective etching of defects introduced by ion beam impact. Several groups, including the authors have followed this idea [26,31-37]. Hövel and Barke studied the morphology and electronic structure of gold clusters in great detail [38].

We have shown in a recent contribution that small clusters can indeed be stabilized very effectively in nanopits and we could show that $\mathrm{Au}$ nanoclusters with a diameter of $5 \mathrm{~nm}$ are stable under electrochemical conditions (i.e. $0.5 \mathrm{M} \mathrm{H}_{2} \mathrm{SO}_{4}$ ) [39].

In this contribution we extend this work, characterizing the stability of Au nanoparticles under high temperature conditions in air and optimizing the particle density on the surface for future applications in catalysis. Small gold clusters with a diameter $\leq 6 \mathrm{~nm}$ are fixed in these nanopits showing a beadlike particular nanostructure. The nanosized gold deposits are characterized by scanning tunneling microscopy (STM) in air.

\section{Experimental setup}

The experimental part has been described in detail elsewhere $[39,40]$ and only a short summary is given here. 


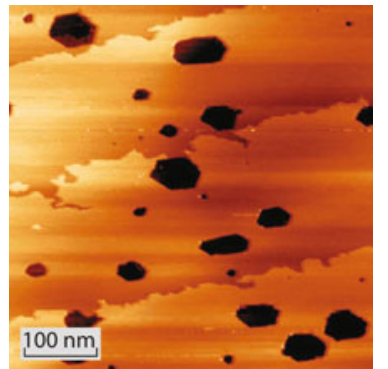

(a)

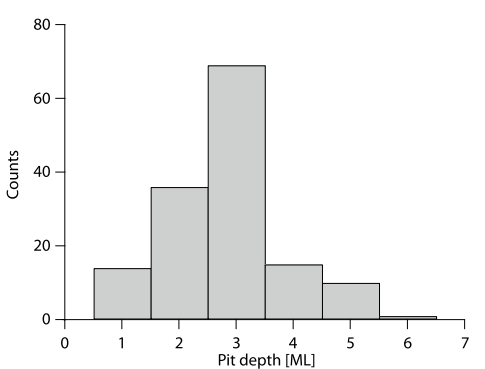

(b)

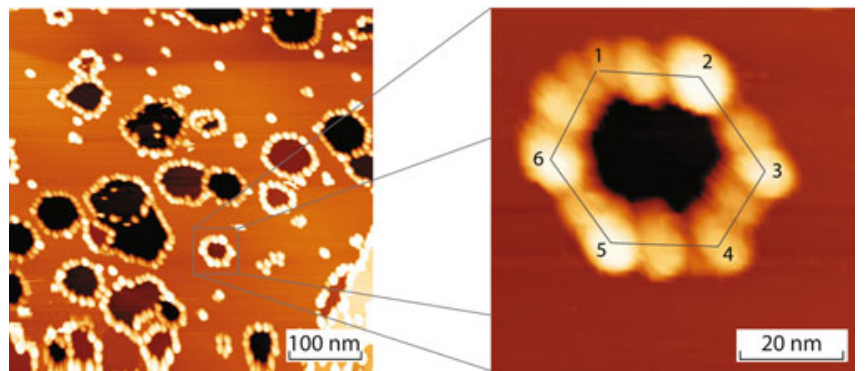

(a)

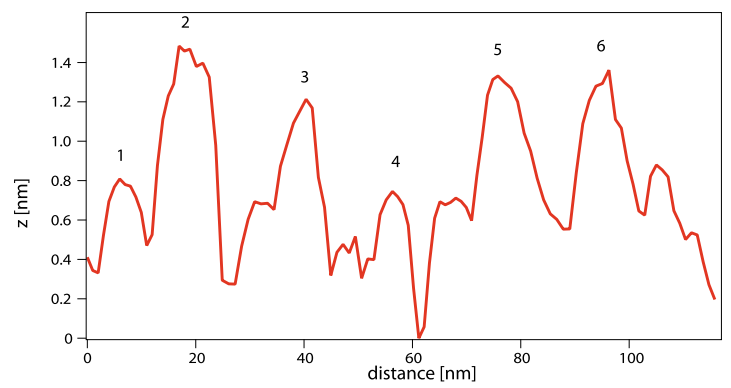

(b)

Fig. 1. (Color online) STM image of nanopits in HOPG. Incident kinetic energy: $E_{\text {kin }}=3 \mathrm{keV}$; impact density: $1000 \mu \mathrm{m}^{-2}$. (a) STM image of pits after etching, $V_{\text {gap }}=0.5 \mathrm{~V}, I_{\mathrm{T}}=0.5 \mathrm{nA}$ $(500 \mathrm{~nm} \times 500 \mathrm{~nm})$. (b) Histogram presenting the pit depth for $\mathrm{Au}_{5}^{+}$clusters at impact energy of $3 \mathrm{kV}$. Mean pit depth is $2.84 \mathrm{ML}$.

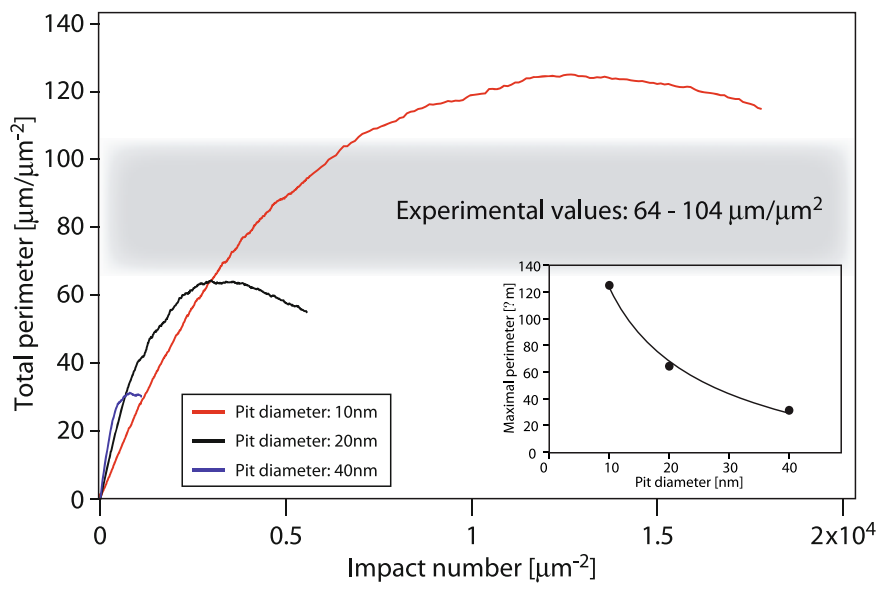

Fig. 2. (Color online) Simulation of the total pit perimeter vs. impact number and pit dimensions. A maximum of $125 \frac{\mu \mathrm{m}}{\mu \mathrm{m}^{2}}$ has been found for pit diameters of $10 \mathrm{~nm}$. Experimental values (grey highlight) for pit diameters of approx. $15 \mathrm{~nm}$ fit with the simulation. Inset: the maximal perimeter decreases with increasing pit diameter following a square-root behavior.

Defects in HOPG are created by $\mathrm{Au}_{5}^{+}$clusters which have been implanted in $\mathrm{HOPG}$ at $3 \mathrm{kV}$ under high vacuum conditions at room temperature. The combination of cluster size and impact energy results in an effective defect depth of 3 monolayers [41].

The etching stage is performed in a vacuum furnace $\left(p<1 \times 10^{-4}\right.$ mbar $)$ at $950 \mathrm{~K}$. During etching, the temperature varies by $\pm 20 \mathrm{~K}$. Typical etching durations are in the order of $10 \mathrm{~min}$ at an oxygen pressure of $80 \pm 3$ mbar. Once the sample attained room temperature, it is examined by scanning tunneling microscopy (STM) in air to control the quantity and the size of the pits. Figure 1a shows an example of the etch pits (estimated pit diameter between 10 to $50 \mathrm{~nm}$ ) and Figure 1b the depth distribution which yields a mean value of $2.84 \mathrm{ML}$.

The number of primary impacts has been chosen to optimize the total pit rim length which itself depends on the mean diameter. In order to find the number of primary impacts for a maximal total rim length, we simulate random

Fig. 3. (Color online) (a) STM image of gold deposited on structured HOPG. $V_{\text {gap }}=1.4 \mathrm{~V}, I_{\mathrm{T}}=100 \mathrm{pA}$ $(500 \mathrm{~nm} \times 500 \mathrm{~nm})$. The inset on the right shows a single pit decorated with gold nanoparticles. In the line profile (b) it can be seen that the edge particles are higher than particles at straight rims.

impacts on a surface and subsequent (circular) etching to a chosen pit diameter. The obtained total rim length are reported in Figure 2 for diameters between 10 and $40 \mathrm{~nm}$. The inferior limit is due to experimental limits. Smaller pits are very difficult to reproduce in a reliable way. With increasing diameter, the total available perimeter length decreases with a square-root behavior (inset in Fig. 2). The comparison of the simulation results with the experimental values shows a good match: the total perimeter (simulation) for pits of 10 to $20 \mathrm{~nm}$ is situated between 64 and $125 \frac{\mu \mathrm{m}}{\mu \mathrm{m}^{2}}$ as shown on Figure 2 whereas the experimental values measured on different samples vary between 63 and $104 \frac{\mu \mathrm{m}}{\mu \mathrm{m}^{2}}$ for the mentioned pit diameters (grey zone). The number of impacts per unit surface are contained between 3500 and 11000 impacts per $\mu \mathrm{m}^{2}$.

Gold is deposited on the nanostructured surface by physical vapor deposition (PVD). The samples are heated to $673 \mathrm{~K}$ under vacuum at a pressure of $5 \times 10^{-6}$ mbar. The thermal energy of the gold atoms provides soft landing conditions without any defect creation on the HOPG surface. Elevated temperatures of the sample during the deposition process enhance the mobility of gold on the graphite surface. Gold particles move randomly on the surface and nucleate at strong binding sites. The total amount of gold is monitored with a quartz-crystal microbalance.

After deposition, the samples are cooled down in a nitrogen atmosphere. Figure 3a shows an STM image of a graphite sample after gold deposition. One can see gold 


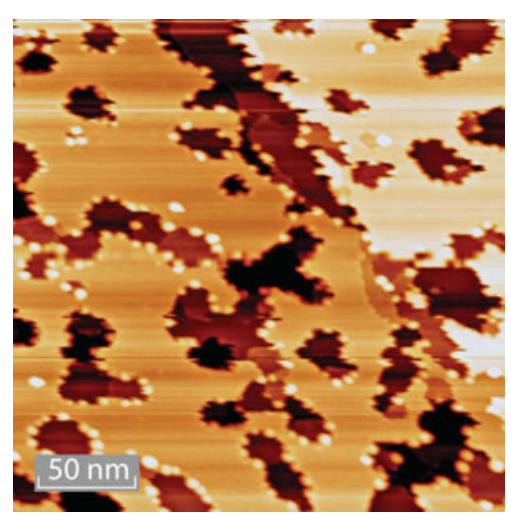

Fig. 4. (Color online) STM image after deposition of a small gold quantity. The clusters are located on the rim but do not form continuous corrals. $V_{\text {gap }}=$ $0.7 \mathrm{~V}, I_{\mathrm{T}}=50 \mathrm{pA}$ $(250 \mathrm{~nm} \times 250 \mathrm{~nm})$.

particles all over the step edges and the rim of the pits. The mean diameter of the particles is $\mathrm{d}=2.5 \pm 0.3 \mathrm{~nm}$ with a density of $\delta=3800 \mu \mathrm{m}^{-2}$.

\section{Results and discussion}

\subsection{Corral formation}

Gold deposited on nanostructured graphite has been found to nucleate in form of small nanoparticles at step edges and more specifically at the rim of pits $[34,38,39,42]$. Existing studies focus on monolayer high step edges or rims by etching natural defects [42], low coverage of multilayer deep pits $[34,38,39]$ and large clusters which completely saturated small pits with gold [34]. In this contribution we focus on the formation of small nanoclusters which form stable beads on multilayer high graphite edges.

At low gold loadings, the particles do not fill up the complete available rim space but form individual clusters independent from each other. Their preferred positions are the corners of the pits where the interaction between graphite and gold cluster is the strongest. Figure 4 shows an STM image with a very small gold load $\left(1.4 \times 10^{14} \frac{\mathrm{atoms}}{\mathrm{cm}^{2}}\right)$. This result is in agreement with studies from Hövel on monolayer high pits [34].

Increasing the coverage up to $2.6 \times 10^{15} \frac{\mathrm{atoms}}{\mathrm{cm}^{2}}$ leads to the formation of equally spaced beads aligned on the rim of the pits, as can be seen in Figure 3a. Notice however that the stronger correlated corner clusters are imaged significantly higher, as it is also shown in the line profile in Figure 3b.

\subsection{Cluster size of corral particles}

Starting from small particles for deposition of low gold quantities, the cluster size increases with increasing gold quantity. Due to inevitable tip convolution effects only apparent cluster heights are given in Figure 5. Notice that these heights are measured from the bottom of the pits. Assuming the clusters as truncated spheres with a diameter to height ratio of 1.4 as reported by Hövel and Barke [38] we can estimate the total number of

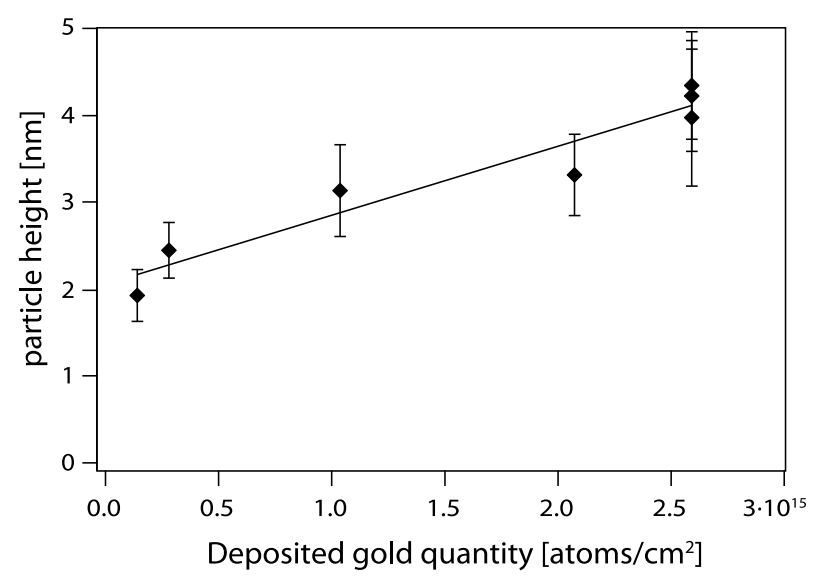

Fig. 5. Particle height vs. deposited gold quantity. The particle size is linearly proportional to the gold quantity.

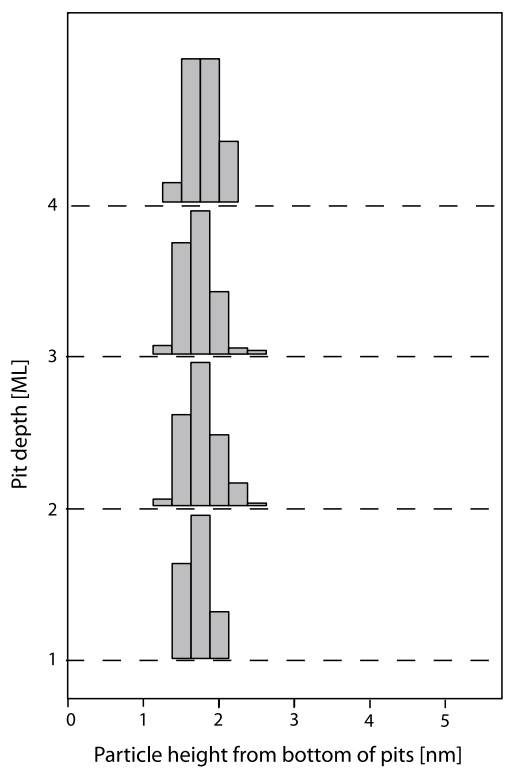

Fig. 6. Particle height measured from the bottom of the pits as a function of pit depth.

atoms/cluster ranging from 480 to 5600 using the density of fcc Au. The ratio of the Au cluster volume agrees nicely with the ratio of the deposited Au quantity.

Interesting enough, the cluster height distribution (CHD) does not depend on the pit depth. Figure 6 shows the CHD of rim stabilized particles as a function of pit depth. For this particular gold load $\left(5 \times 10^{14} \frac{\text { atoms }}{\mathrm{cm}^{2}}\right)$ we find a mean height comprised between 1.72 and $1.81 \mathrm{~nm}$. Clearly the center of the cluster height distribution does not change. The width of the height distribution is changing slightly which is explained by the reduced number of particles counted for the statistics in the $4 \mathrm{ML}$ deep pit. This result is surprising since we would expect the increased number of dangling bonds on the rim of the pit to have an influence on the particle morphology.

While the cluster size increases with increasing $\mathrm{Au}$ load, this is not the case, at least for the quantities employed here, for the rim density (i.e. number of Au clusters per $\mu \mathrm{m}$ of rim length). Figure 7 shows the particle number per $\mu \mathrm{m}$ of rim versus deposited gold quantity. The number 


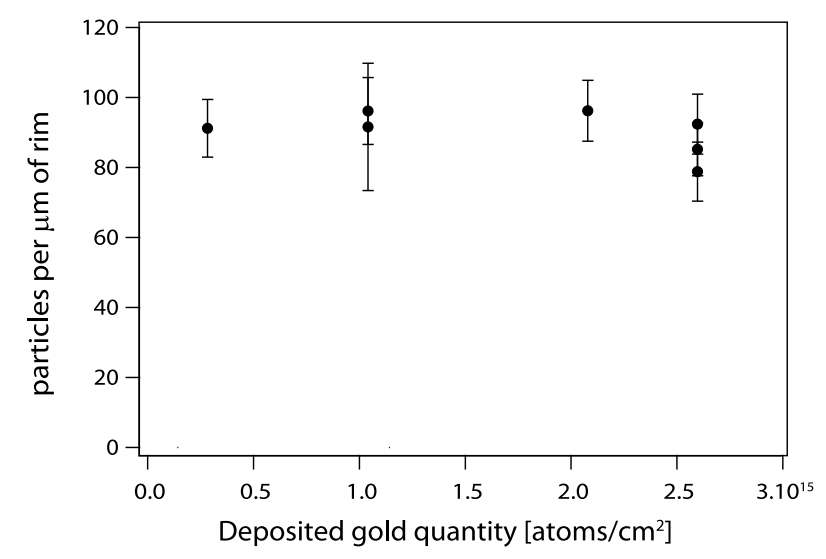

Fig. 7. Gold quantity deposited on HOPG vs. the number of particles on 1 micrometer of rim. The constant value of approx. 100 particles per unit length indicates that the gold quantity is not the primary limiting factor for the particle number.

of particles remains roughly constant for all studied gold quantities. When gold is evaporated on HOPG at elevated temperature $(673 \mathrm{~K})$, atoms occupy individually all available dangling bonds. Additional atoms attach to existing nanoparticles and increase their size. Clusters thus grow uniformly in size. At very big gold loads, the clusters change shape from circular to slightly elliptic (see Fig. 3a). Their growth is laterally limited by the presence of the neighboring cluster. The particle increase toward the center of the pits. We did not observe the merging of particles, as it has been observed by McBride et al. [42]. We suppose that the actual deposited gold loads were not sufficiently high to observe this behavior. This also answers the question whether the clusters on a rim touch each other or if there is open space between. Assuming a rim density of 100 clusters per $\mu \mathrm{m}$ we obtain an open space depending on the Au load which varies between $3.9 \mathrm{~nm}$ and $5.6 \mathrm{~nm}$. This means that, even though the STM image shows a closed chain of clusters, the particles are clearly separated from each other. This is an important fact that has to be considered when the catalytic activity of gold clusters will be discussed [43].

\subsection{Cluster stability}

One of the main purposes of this contribution is the study of the thermal evolution of gold clusters stabilized in nanopits. This evolution has been studied for several annealing temperatures. The sample has been introduced into a furnace at ambient pressure and was heated during $15 \mathrm{~min}$. Heating cycles enhance the mobility of gold and in consequence decrease the number of particles with increasing temperature. Remind however that the particles are born under high vacuum conditions at a substrate temperature of $673 \mathrm{~K}$. From this point of view we expect no thermal activated morphology change up to this temperature. However the exposure to environmental gases, especially oxygen might result in a change of the morphology as this is for example the case for the HOPG etching of

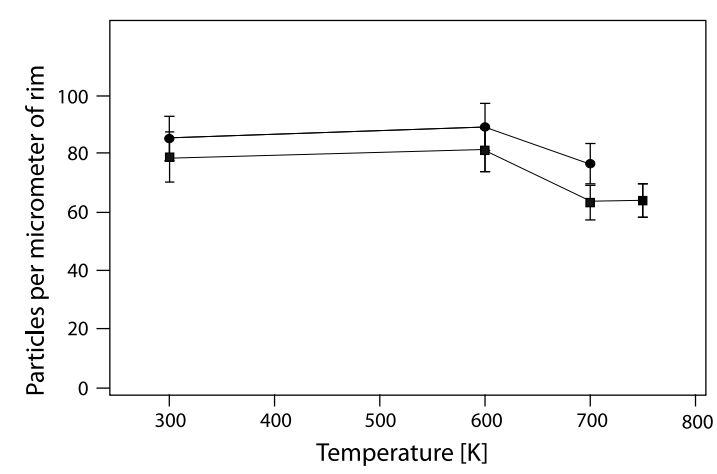

(a)

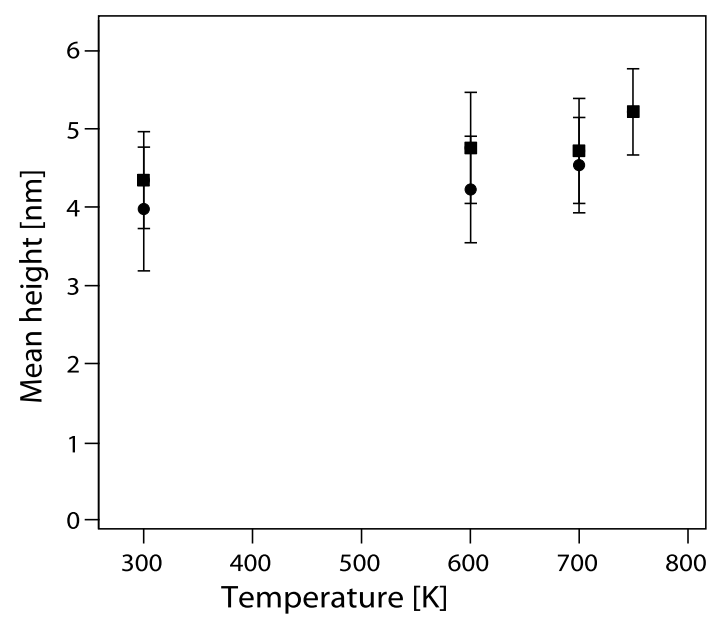

(b)

Fig. 8. (a) Particle number vs. annealing temperature, (b) particle size as measured by the apparent height vs. annealing temperature.

pits which does not take place under vacuum. Figure 8a shows the particle number versus the annealing temperature and Figure $8 \mathrm{~b}$ the associated mean heights. Until a temperature of $600 \mathrm{~K}$, the particle number and the particle volume stay constant. This can only be expected when the $\mathrm{Au}$ clusters are resistant to any oxygen etching or other gases $\left(\mathrm{CO}, \mathrm{H}_{2} \mathrm{O}\right)$ present in the atmosphere. Looking at the heights as a function of annealing temperature (Fig. 8b) we observe a slight increase only above $700 \mathrm{~K}$. This would suggest that there is no reaction driven morphology change up to this temperature. However, while the mean height stays constant over the observed temperature range, we observe a sensitive narrowing of the height distribution as shown in Figure 9. This suggests that for a given Au loading we do find a particular stable Au cluster in height and diameter.

\subsection{Channel etching}

HOPG is inert to oxygen etching up to a temperature of $920 \mathrm{~K}$. However it is well established that metallic particles can catalytically activate this etching process at much lower temperatures. Numerous systems essentially 


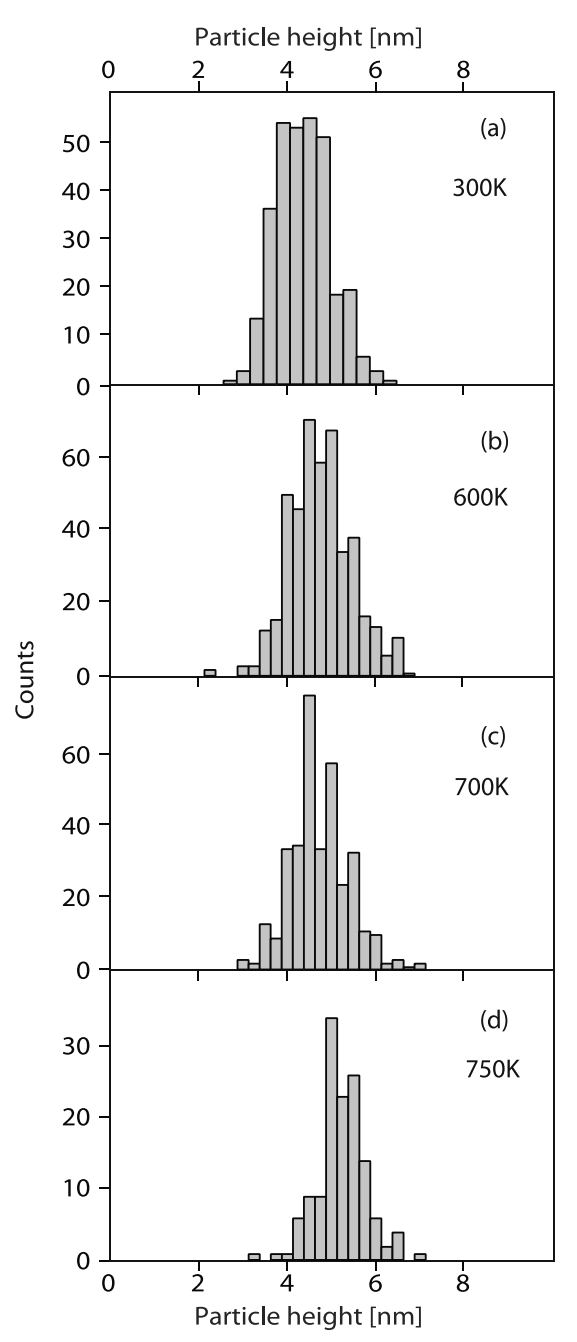

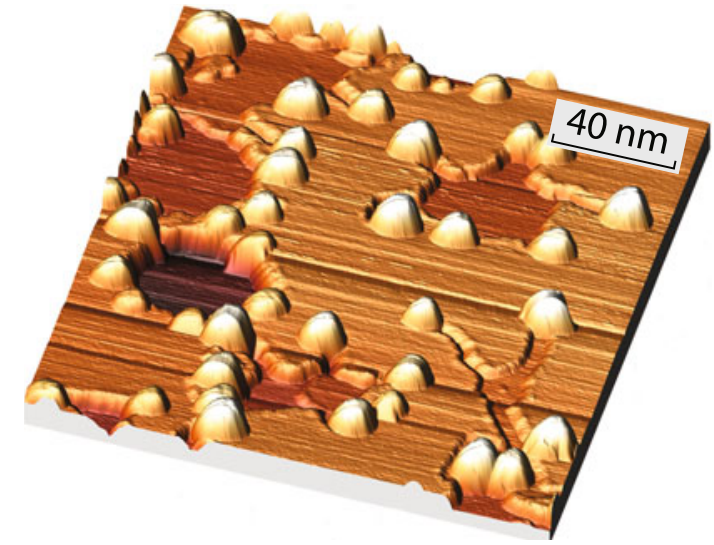

Fig. 10. (Color online) STM image of gold nanoparticles on structured HOPG after annealing to $700 \mathrm{~K}$. $V_{\text {gap }}=0.7 \mathrm{~V}$, $I_{\mathrm{T}}=50 \mathrm{pA}(170 \mathrm{~nm} \times 170 \mathrm{~nm})$.

\section{Conclusion}

We have investigated the morphology of Au clusters grown in multilayer deep HOPG nanopits at a size range comprised between 4 and $6 \mathrm{~nm}$. At intermediate coverage these clusters arrange to form beads with a constant density and a very narrow size distribution. The spacing between these beads varies between 3.9 and $5.6 \mathrm{~nm}$ depending on the gold load. The height is essentially independent on the pit depth i.e. the number of fixing dangling bonds. The $\mathrm{Au}$ nanoclusters are perfectly stable against thermal annealing under ambient conditions up to $750 \mathrm{~K}$ which means that they serve only as spectators in chemical reactions. The size distribution sharpens at higher temperatures indicating a particular stability for a given size. The $\mathrm{Au}$ nanoclusters catalyze the etching of the graphene layers and form channels which have identical depths as the initial confining pits.

on transition metal particles have been published over the last 50 years [44-60]. They all observed local particleenhanced etching of graphite. However only very few data exist on the etching behavior of gold nanoparticles.

The only indication of a catalytic activity of gold nanoparticles was studied by Watanabe [53]. Based on scanning electron microscopy (SEM) investigations he concluded that $\mathrm{Au}$ particles dig themselves into the HOPG layers which, as will be shown below, is not true. Figure 10 shows an STM picture in three-dimensional representation of pit stabilized Au clusters after annealing in air to $700 \mathrm{~K}$. The clusters have not changed size and form (see Figs. 8a and 8b) but clearly penetrated horizontally into the graphene layer.

Notice that the etching channel has always the same depth as the initial confining pit which means that no etching across the graphene layers takes place. This is in contrast to the process proposed by Watanabe [53]. The width of the channels which can be measured to much better precision than the particles confirm nicely the truncated sphere approach by Hövel and Barke [38], when we accept that the channel width corresponds to the particle diameter.
This work was supported by the Swiss National Science Foundation

\section{References}

1. G.R. Bamwenda, S. Tsubota, T. Nakamura, M. Haruta, Catal. Lett. 44, 83 (1997)

2. M. Haruta, Catal. Today 36, 153 (1997)

3. Z.Y. Li, N.P. Young, M. Di Vece, S. Palomba, R.E. Palmer, A.L. Bleloch, B.C. Curley, R.L. Johnston, J. Jiang, J. Yuan, Nature 451, 46 (2008)

4. M. Turner, V.B. Golovko, O.P.H. Vaughan, P. Abdulkin, A. Berenguer-Murcia, M.S. Tikhov, B.F.G. Johnson, R.M. Lambert, Nature 454, 981 (2008)

5. A. Herzing, C. Kiely, A. Carley, P. Landon, G. Hutchings, Science 321, 1331 (2008)

6. M.E. Vaida, T. Gleitsmann, R. Tchitnga, T.M. Bernhardt, Phys. Stat. Sol. B 247, 1139 (2010)

7. M. Haruta, T. Kobayashi, H. Sano, N. Yamado, Chem. Lett. 16, 405 (1987)

8. Nanocatalysis, edited by U. Heiz, U. Landman (Springer, Berlin, 2007) 
9. S. Lang, T. Bernhardt, Int. J. Mass Spectrom. 286, 39 (2009)

10. M. Valden, X. Lai, D. Goodman, Science 281, 1647 (1998)

11. A. Sanchez, S. Abbet, U. Heiz, W.D. Schneider, H. Hakkinen, R. Barnett, U. Landman, J. Phys. Chem. A 103, 9573 (1999)

12. S. Lee, C. Fan, T. Wu, S.L. Anderson, J. Am. Chem. Soc. 126, 5682 (2004)

13. S. Lee et al., Angew. Chem. Int. Ed. 48, 1467 (2009)

14. S.J. Carroll, R.E. Palmer, P.A. Mulheran, S. Hobday, R. Smith, Appl. Phys. A 67, 613 (1998)

15. S.J. Carroll, K. Seeger, R.E. Palmer, Appl. Phys. Lett. 72, $305(1998)$

16. G. Francis, I. Goldby, L. Kuipers, B. Von Issendorff, R. Palmer, Journal of the Chemical Society-Dalton Transactions 5, 665 (1996)

17. I.M. Goldby, L. Kuipers, B. von Issendorff, R.E. Palmer, Appl. Phys. Lett. 69, 2819 (1996)

18. A. Baldansuren, H. Dilger, R.A. Eichel, J.A. van Bokhoven, E. Roduner, J. Phys. Chem. C 113, 19623 (2009)

19. G.A. Somorjai, A.M. Contreras, M. Montano, R.M. Rioux, Proc. Natl. Acad. Sci. 103, 10577 (2006)

20. A. Kulkarni, R.J. Lobo-Lapidus, B.C. Gates, Chem. Commun. 46, 5997 (2010)

21. X. Tong, L. Benz, P. Kemper, H. Metiu, M.T. Bowers, S.K. Buratto, J. Am. Chem. Soc. 127, 13516 (2005)

22. K. Bromann, H. Brune, C. Felix, W. Harbich, R. Monot, J. Buttet, K. Kern, Surf. Sci. 377, 1051 (1997)

23. K. Bromann, C. Felix, H. Brune, W. Harbich, R. Monot, J. Buttet, K. Kern, Science 274, 956 (1996)

24. P. Convers, R. Monot, W. Harbich, submitted

25. H. Jodicke, R. Schaub, R. Monot, J. Buttet, W. Harbich, Surf. Sci. 475, 1 (2001)

26. S.J. Carroll, S.G. Hall, R.E. Palmer, R. Smith, Phys. Rev. Lett. 81, 3715 (1998)

27. S. Gibilisco, M. Di Vece, S. Palomba, G. Faraci, R. Palmer, J. Chem. Phys. 125, 84704 (2006)

28. C.M. Grimaud, R. Palmer, J. Phys. Cond. Mat. 13, 1869 (2001)

29. G. Braeuchle, S.R. Schneider, D. Illig, R.D. Beck, H. Schreiber, M.M. Kappes, Nucl. Instr. Methods B 112, 105 (1996)

30. G. Brauchle, S.R. Schneider, D. Illig, J. Rockenberger, R.D. Beck, M.M. Kappes, Appl. Phys. Lett. 67, 52 (1995)

31. F. Ghaleh, R. Koster, H. Hövel, L. Bruchhaus, S. Bauerdick, J. Thiel, R. Jede, J. Appl. Phys. 101, 044301 (2007)

32. H. Hövel, T. Becker, A. Bettac, B. Reihl, M. Tschudy, E.J. Williams, J. Appl. Phys. 81, 154 (1997)
33. I. Barke, H. Hövel, Phys. Rev. Lett. 90, 166801 (2003)

34. T. Irawan, I. Barke, H. Hövel, Appl. Phys. A 80, 929 (2005)

35. S. Pratontep, P. Preece, C. Xirouchaki, R. Palmer, C. Sanz-Navarro, S. Kenny, R. Smith, Phys. Rev. Lett. 90, 055503 (2003)

36. C. Sanz-Navarro, R. Smith, D. Kenny, S. Pratontep, R. Palmer, Phys. Rev. B 65, 165420 (2002)

37. L. Seminara, Ph.D. thesis, École Polytechnique Fédérale de Lausanne, 2004

38. H. Hövel, I. Barke, Prog. Surf. Sci. 81, 53 (2006)

39. M. Limat, G. Foti, M. Hugentobler, R. Stephan, W. Harbich, Catal. Today 146, 378 (2009)

40. H. Jodicke, R. Schaub, A. Bhowmick, R. Monot, J. Buttet, W. Harbich, Rev. Sci. Instrum. 71, 2818 (2000)

41. L. Seminara, P. Convers, R. Monot, W. Harbich, Eur. Phys. J. D 29, 49 (2004)

42. J.D. McBride, B. Van Tassell, R.C. Jachmann, T.P. Beebe, J. Phys. Chem. B 105, 3972 (2001)

43. M. Hugentobler, S. Bonanni, C. Xia, W. Harbich, submitted

44. G. Hennig, J. Inorg. Nucl. Chem. 24, 1129 (1962)

45. A. Tomita, N. Sato, Y. Tamai, Carbon 12, 143 (1974)

46. A. Tomita, Y. Tamai, J. Catal. 27, 293 (1972)

47. R.T.K. Baker, J.A. France, L. Rouse, R.J. Waite, J. Catal. 41, 22 (1976)

48. R.T.K. Baker, R.D. Sherwood, J. Catal. 61, 378 (1980)

49. R.T.K. Baker, R.D. Sherwood, J. Catal. 70, 198 (1981)

50. P.J. Goethel, R.T. Yang, J. Catal. 119, 201 (1989)

51. H.Y. Huang, R.T. Yang, J. Catal. 185, 286 (1999)

52. S. Konishi, W. Sugimoto, Y. Murakami, Y. Takasu, Carbon 44, 2338 (2006)

53. H. Watanabe, Jpn J. Appl. Phys. 32, 2809 (1993)

54. F. Schäffel, J.H. Warner, A. Bachmatiuk, B. Rellinghaus, B. Büchner, L. Schultz, M.H. Rümmeli, Phys. Stat. Sol. B 246, 2540 (2009)

55. Y. Takasu, S. Konishi, R. Miyoshi, K. Nukii, T. Matsuse, W. Sugimoto, Y. Murakami, Chem. Lett. Jpn 34, 1008 (2005)

56. N. Severin, S. Kirstein, I.M. Sokolov, J.P. Rabe, Nano Lett. 9, 457 (2009)

57. S.S. Datta, D.R. Strachan, S.M. Khamis, A.T.C. Johnson, Nano Lett. 8, 1912 (2008)

58. L.C. Campos, V.R. Manfrinato, J.D. Sanchez-Yamagishi, J. Kong, P. Jarillo-Herrero, Nano Lett. 9, 2600 (2009)

59. L. Ci, Z. Xu, L. Wang, W. Gao, F. Ding, K. Kelly, B. Yakobson, P. Ajayan, Nano Research 1, 116 (2008)

60. F. Ding, P. Larsson, J.A. Larsson, R. Ahuja, H. Duan, A. Rosen, K. Bolton, Nano Lett. 8, 463 (2008) 